\title{
ROY, Ananya \& ONG, Aihwa. Worlding Cities: Asian Experiments and the art of being global
}

\author{
Marcelo A. de A. Teixeira
}

\section{(2) OpenEdition \\ 1 Journals}

Edição electrónica

URL: http://journals.openedition.org/aa/544

DOI: $10.4000 /$ aa. 544

ISSN: 2357-738X

Editora

Programa de Pós-Graduação em Antropologia Social (UnB)

\section{Edição impressa}

Data de publição: 31 dezembro 2013

Paginação: 267-270

ISSN: 0102-4302

\section{Refêrencia eletrónica}

Marcelo A. de A. Teixeira, «ROY, Ananya \& ONG, Aihwa. Worlding Cities: Asian Experiments and the art of being global », Anuário Antropológico [Online], v.38 n.2 | 2013, posto online no dia 01 fevereiro 2014, consultado o 28 abril 2021. URL: http://journals.openedition.org/aa/544 ; DOI: https://doi.org/ 10.4000/aa.544

Este documento foi criado de forma automática no dia 28 abril 2021.

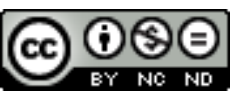

Anuário Antropológico is licensed under a Creative Commons Atribuição-Uso Não-Comercial-Proibição de realização de Obras Derivadas 4.0 International. 


\title{
ROY, Ananya \& ONG, Aihwa. Worlding Cities: Asian Experiments and the art of being global
}

\author{
Marcelo A. de A. Teixeira
}

\section{REFERÊNCIA}

ROY, Ananya \& ONG, Aihwa. 2011. Worlding Cities: Asian Experiments and the art of being global. Oxford: Wiley Blackwell. $352 \mathrm{pp}$.

Com o crescimento econômico e urbano, as cidades da Ásia se tornaram modelo de gerenciamento e urbanismo de relevância global. Xangai, Dubai, Singapura e Hong Kong rivalizam hoje com clássicas cidades globais (como Paris, Londres e Nova York) em renovação urbana, modelos arquitetônicos e capacidade de captação dos fluxos globais de investimento e acumulação de capital, indicando a emergência do eixo econômico mundial para o Leste. É sobre a emergência das cidades asiáticas no cenário global que a antropóloga malaia de origem chinesa Aihwa Ong e a urbanista indiana Ananya Roy (ambas professoras da Universidade de Berkeley, EUA) editaram Worlding Cities: Asian Experiments and the art of being global, uma coletânea de artigos multidisciplinares que tratam da expansão urbana na Ásia contemporânea e globalizada, dos seus efeitos, discursos e práticas.

2 Roy e Ong iniciam o livro criticando duas principais abordagens dominantes dos parâmetros e das perspectivas de investigação das cidades contemporâneas: a política econômica da globalização neoliberal e o foco pós-colonial na subalternidade, ambas de pedigree marxista. A primeira encara as cidades como um campo de acumulação de capital e luta de classes. A segunda, as cidades fora do mundo euro-americano como guiadas apenas por resistências subalternas a diferentes modos de dominação provenientes deste. Para as pesquisadoras, as experiências urbanas asiáticas contemporâneas nos guiariam para ver as cidades como locais em constante formação, 
em disparatadas conexões sujeitas às forças locais, nacionais e globais, em rivalidade e espelhamento com outras cidades. Convergem, assim, para Michael Peter Smith: a cidade seria uma "encruzilhada de relações sociais constituídas das interações de atores locais, nacionais e transnacionais, e das redes pelas quais estes operam" (2011:184). Segundo as autoras, ambas as abordagens (capitalista e pós-colonial) são limitadas para entender a Ásia urbana contemporânea, já que não levaria em consideração que o urbano é uma paisagem animada por uma variedade de instituições, atores e práticas locais e transnacionais, sendo necessário entender os casos estudados como ao mesmo tempo heterogeneamente particulares e irredutivelmente globais.

Worlding cities seria como uma identificação de práticas e projetos que indicam a visão de um mundo em formação, de um devir que imagina e forma visões e configurações sociais alternativas, e que remapeia relações de poder em diferentes escalas e localidades, além de formar massas críticas em cidades (já que são nestas em que os processos de "worlding" são corporificados). 0 exato ato de reimaginar e redesenhar um local urbano (alterando infraestrutura, possibilidades políticas e estilos estéticos) seria, por definição, um ato aspiracional, experimental e especulativo.

Roy e Ong apontam para três estilos de ser global: modelamento, inter-referência e associações. A renovação dos centros urbanos asiáticos originou a circulação de modelos urbanos que não têm suas principais referências no Ocidente. $O$ modelamento: a emergência de Xangai, Hong Kong, Dubai e Singapura forneceu um modelo replicável de reformulações urbanas que são utilizados e remixados entre si por novos centros urbanos da região ansiosos por inserção nos fluxos globais de investimentos imobiliários, industriais, culturais e corporativos. A modelagem passa a ser não apenas uma tecnologia de replicação construtiva, mas uma ferramenta política de transformação do ambiente construído e do espírito social dos novos centros urbanos. Inter-referências: A partir do exemplo de sucesso de determinada cidade, seu modelo então é exportado para outros centros que competem e comparam-se entre si, formando uma rede de cidades inter-referenciadas. Seriam práticas de citação, alusão, comparação e competição. Associações: as cidades asiáticas se tornam experimentações de formas arquitetônicas e sociais, onde neoliberalismo e ativismo social misturam-se em complexos cenários de múltiplas coalizões, que tanto desestabilizam quanto formam novas configurações de sociedade urbana.

5 A primeira parte do livro reúne os artigos nos quais o "Modelamento" é sua pauta comum. Começa com o artigo de Chua Beng Huat sobre a "griffe" Singapura: por ser um caso bem-sucedido de cidade-estado, teria se tornado apta a exportar seu modelo de planejamento urbano para o restante da Ásia, envolvendo atores políticos e econômicos nessa exportação, como, por exemplo, para a cidade chinesa de Dalian. Esta última é analisada por Lisa Hoffman em seu artigo sobre as interseções de políticas estatais, replicação de modelos, ecologia e sustentabilidade, em que um novo modelo de urbanismo "verde" é também capaz de moldar uma cidadania "ecofriendly" totalitária: o comportamento e a subjetividade do morador estariam subjugados pela necessidade de serem "sustentáveis". O artigo de Gavin Shatkin, "Planning Privatopolis", analisa uma prática asiática implicada nos fluxos de investimentos financeiros globais que estaria sendo exportada para além da Ásia: os mega projetos urbanos privados. As "privatopolis" estariam inseridas em uma complexa rede global de investimentos (abrangendo desde escritórios de urbanismo a Estados-nações) e em uma específica agenda desenvolvimentista com o objetivo de atingir metas estatais de globalização da 
economia e metas corporativas de comoditização em larga escala do espaço urbano (por meio do investimento imobiliário). Shannon May analisa o caso da cidade chinesa de Huangbaiyu, uma investida binacional entre China e Estados Unidos, destinada a ser um modelo de cidade verde, entretanto, criando uma matriz exclusivista que também definiria estilos de vida tidos como reprováveis, perpetuando formas de dominação e de poder.

6 A segunda parte do livro reúne artigos que abordam a inter-referência das experiências urbanas asiáticas e a replicação dessas experiências em outros contextos nacionais. Helen F. Siu explora uma possível marginalização da outrora opulenta Hong Kong em face da emergência de novas metrópoles chinesas (Shenzen, Guangzhou) e de Dubai. Entretanto, Hong Kong e Dubai, mais do que rivais, se tornaram nós sistêmicos e conjugados do neoliberalismo islâmico e asiático, fomentando uma rede de investimentos mútuos entre as duas metrópoles. Chad Haines explora em seu artigo a "marca" Dubai, intencionalmente manufaturada para proporcionar visibilidade global, consumida por classes e cidades emergentes por toda a Ásia, Oriente Médio e África, tornando-se referência para diversos projetos urbanos nessas regiões. $O$ imaginário proporcionado por Dubai se transformaria também em agente de mudança de realidades locais: Dubai não seria apenas uma cidade dos Emirados Árabes, mas, simultaneamente, uma cidade filipina, indiana, paquistanesa, e não poderia ser dissociada do neoliberalismo modernizador do mundo islâmico. Em seguida, Lowry e McCann analisam a exportação de modelos urbanos asiáticos na cidade de Vancouver, no Canadá, e sua genealogia com modelos oriundos de Dubai, e de que maneira a identidade, a arquitetura e o comportamento dos habitantes de Vancouver estariam sendo afetados por um modelo urbano sem referência no Ocidente. Em seu artigo, Aihwa Ong chama a construção de mega arranha-céus de hyperbuilding, definido como um processo no qual se projetam identidades urbanas (com o objetivo de prepará-las para um futuro promissor) e como uma cristalização de agentes de poder no cenário urbano.

7 A terceira parte do livro coleta artigos sob a alcunha de "novas solidariedades". Aqui, Roy e Ong pretendem indicar como grupos sociais se uniriam em resistências diante dos projetos urbanos asiáticos, geralmente impostos de cima para baixo, sem mediação da sociedade civil. Michael Goldman especula em seu artigo qual será a próxima cidade global, analisando as conexões entre as reformas urbanas em curso na Índia e a expansão do capital de origem árabe para além de Dubai, onde um "urbanismo transnacional" (ou "urbanismo especulativo") visa lucrar com a expansão urbana asiática. Ananya Roy afirma que até em governos de esquerda, como em Kolkata (com governo do Partido Comunista Indiano), a cooptação neoliberal se faria presente, ao levar o governo a utilizar suas ferramentas de poder objetivando inserir a cidade nos fluxos globais de investimentos. Entretanto, ao ameaçar populações de desapropriação beneficiando grandes empreiteiras, o governo atrairia para si a resistência organizada de movimentos sociais.

8 Na conclusão, Ananya Roy sugere considerar o urbanismo "pós-colonial" não como uma condição urbana, mas como uma atitude crítica deconstrutivista. Dessa maneira, convida a desconstruir binômios empregados pelo pós-colonialismo: espaço metropolitano/colonial, centro/periferia, subalternidade e primazia. Para Roy, "worlding" seria um conjunto de três práticas implicadas na produção de novas cidades: velocidade (Shenzen), histeria (Dubai) e "sonhos massificados" (Mumbai). 
Seriam práticas que visam centralizar, gerar e aproveitar regimes globais de valoração urbana em experimentos urbanos interconectados, criando um urbanismo interasiático. Roy dirige-se aos conceitos pós-coloniais do que seria a Ásia, a África, a América: seriam discursos, narrativas geográficas que induziriam a generalizações. A cidade pós-colonial não seria hoje uma sombra das metrópoles, não existiria apenas em um "depois" da Colônia, mas sim uma combinação de diferentes temporalidades, atores, instituições e narrativas. Em seguida, Roy sugere o urbanismo brasileiro como algo distinto do asiático, como sítio de resistência (por causa das preocupações de pesquisadores com as brutais implicações e diferenças dos modelos urbanos nativos em relação à classe, à cor, ao gênero), enquanto o asiático seria a metonímia da prevalência do capital global. Porém, ao ver em um conjunto habitacional popular de São Paulo a replicação de um modelo originário de Singapura (cidade que lhe dá o nome), sugere que a Ásia já não teria limites.

\section{BIBLIOGRAFIA}

SMITH, Michael Peter. 2011. Transnational urbanism: locating globalization. Oxford: Blackwell. p. 184.

\section{AUTORES}

MARCELO A. DE A. TEIXEIRA

FAU/UnB 